\title{
An Intramolecular Schmidt Reaction of an Alkyl Azide with a Carbocation. The Generation and Rearrangement of a Conformationally Restricted Secondary Aminodiazonium Ion.
}

\author{
William H. Pearson* and Jeffrey M. Schkeryantz \\ Department of Chemistry, The University of Michigan, Ann Arbor, MI 48109-1055
}

\begin{abstract}
Abetract: Treatment of azidoalkene 2 with triflic acid produced the bridged bicyclic enamine 3 by an intramolecular Schmidt reaction. Rearrangement of the intermediate aminodiazonium ion $\mathbf{5}$ is completely regioselective.
\end{abstract}

Placement of a strong electron-withdrawing group on a nitrogen atom is a popular way to promote carbon-to-nitrogen rearrangement reactions. 1 We are interested in the system shown in eq. 1 , which is known as the Stieglitz rearrangement. ${ }^{2}$ A considerable amount of recent research has been carried out using rearrangement precursors 1 where $\mathrm{X}=\mathrm{Cl}^{2-6}$ and $\mathrm{X}=\mathrm{OSO}_{2} \mathrm{Ar}$. 2,3d,5,7-9 These are prepared from the corresponding amine (path $a$ ). As a part of our research on the use of azides in organic synthesis, we became interested in an alternate approach based on the generation and rearrangement of secondary aminodiazonium ion intermediates $\left(X=\mathrm{N}_{2}+\right.$ ). An advantage of this method would be the generation of the aminodiazonium ion by the capture of a carbocation with an azide (path $b$ ), resulting in a more convergent overall process. We wish to report the first intramolecular example of such a process using an aliphatic azide.

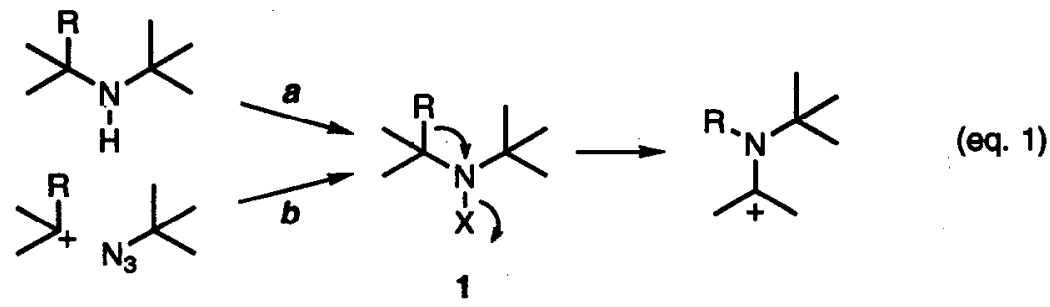

The reaction of hydrazoic acid $\left(\mathrm{HN}_{3}\right)$ with carbocations derived from the reaction of alcohols and alkenes with protic acids generates primary aminodiazonium ions, which undergo rearrangement. This variant of the Schmidt reaction 2,10 has not seen widespread use. Such primary aminodiazonium ions are also produced by protonation of alkyl azides. 2,10 The more useful and well-known versions of the Schmidt reaction involve the reaction of hydrazoic acid with ketones and carboxylic acids, which undergo a more predictable rearrangement. 2,10 For the transformation shown in eq. 1, which proceeds through a secondary aminodiazonium ion, an alkyl azide is required rather than hydrazoic acid. However, the use of alkyl azides 
in any type of Schmidt reaction has long been thought to be unfavorable, 2,10 since azides are only weakly nucleophilic. Recently, Aube reported the intermolecular and intramolecular Schmidt reactions of alkyl azides with ketones. ${ }^{11,12}$ We now wish to report the use of an alkyl azide in the "carbocation" version of the Schmidt reaction. 13

Treatment of azidoalkene 214 with triflic acid in dichloromethane causes rapid gas evolution. Neutralization and isolation affords the bicyclic alkene 3 as the sole product in 71\% purified yield. A mechanism for the formation of 3 is shown below. Protonation of the alkene 2 affords the tertiary benzylic carbocation 4, which is captured by the azide to form the aminodiazonium ion 5 . Migration of an alkyl group leads to the cation 9, which upon proton loss and N-protonation gives the observable ( ${ }^{1} \mathrm{H}$ NMR) enammonium ion 11.<smiles>NCCC1C=C(c2ccc3c(c2)OCO3)CCC1</smiles>

1) $\mathrm{CF}_{3} \mathrm{SO}_{3} \mathrm{H}$ $\mathrm{CH}_{2} \mathrm{Cl}_{2}, 0^{\circ} \mathrm{C}$

2) $\mathrm{NaOH}$

2<smiles>c1cc2c(cc1C1CC3CCCN1CC3)OCO2</smiles><smiles>CC(C)(C1CC(Br)CC(CC#N)C1)S(=O)(=O)O</smiles><smiles>O[N+]1(O)CCC2CCC[C@@H]1[N+]2(O)O</smiles><smiles>N#[N+]N1CCC2CCCC1([Te])C2</smiles>

11

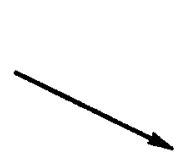<smiles>Br[C@]12[CH]CC[C@@H](CCC1)N2</smiles>

6<smiles>[Al]N1C[C@@H]2CCC[C@H](C2)N1</smiles>

7

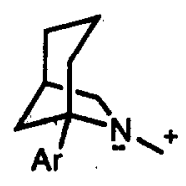

8

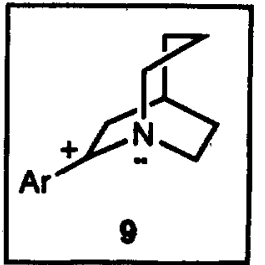<smiles></smiles>

10 
The rearrangement of 2 to 3 has several interesting features. The immediate loss of a proton from 9 to produce the alkene 11 reflects the diminished stabilization of 9 by resonance with the bridgehead nitrogen. Resonance is less effective than a geometrically unconstrained system due to the less than optimal overlap of the nitrogen lone pair with the carbocation p-orbital. Overlap would require an anti-Bredt iminium ion. Therefore, cation 9 is more accurately described as a tertiary benzylic carbocation, and is thus easily deprotonated by even the weak triflate ion. Cations very similar to 9 have been reported by Grob15, Gassman ${ }^{16}$, and Kovacic ${ }^{17}$, who found that there is some interaction of the nitrogen lone pair with the carbocation, but that the interaction is less than what would be expected in an unrestricted system. The deprotonation of 9 to give 3 and reprotonation on nitrogen to give 11 also reflects the unusual geometric restraints in this bicyclic system. Enamines are normally protonated on carbon due to resonance stabilization of the conjugate acid. Protonation of the enamine 3 occurs selectively on nitrogen, since protonation on carbon would produce an iminium ion (i.e., 9) with a diminished ability to participate in resonance. Twisted enamines related to 3 have been previously reported, 18,19 and protonation studies have been carried out. 18

Perhaps the most interesting feature of the rearrangement of 2 to 3 is the complete regioselectivity of the rearrangement. Aminodiazonium ion 5 could produce five possible rearrangement products, shown as $6-10$. Previous work on a variety of $\mathrm{C}$-to-N rearrangements, including Stieglitz and Schmidt rearrangements, does not provide a consistent picture of the regioselectivity of such rearrangements. 20 In particular, rearrangements of aminodiazonium ions derived from hydrazoic acid additions to carbocations (or by protonation of azides) are poor precedents, since free rotation is possible about the $\mathrm{C}-\mathrm{N}$ bond, therefore masking any stereoelectronic effects. The closest analogies to the rearrangement of 5 are the Stieglitz-type rearrangements of secondary $\mathrm{N}$-chloramines and secondary $\mathrm{N}$-sulfonoxyamines, particularly in bridged bicyclic systems. ${ }^{3-9}$ These rearrangements (generally of more rigid bicyclo[2:2.1] systems) are thought to proceed by migration of the group that is antiperiplanar to the $\mathrm{N}-\mathrm{X}$ bond. However, such an analysis in a more flexible ring system such as that in aminodiazonium ion $\mathbf{5}$ is less straightforward, since conformations may be achieved that place several different groups roughly antiperiplanar to the leaving group. In addition, the structure of the aminodiazonium ion itself must be considered. 21 An explanation of the high regioselectivity in the rearrangement of 5 awaits further experimentation.

In conclusion, we have observed the first example of the intramolecular Schmidt reaction of an alkyl azide with a simple carbocation (i.e., rather than an $\alpha$-oxocarbocation11,12). An important aspect of this work is the generation of a geometrically defined aminodiazonium ion, which may allow examination of the stereoelectronic requirements for the rearrangement of such intermediates. Investigation of the intramolecular reaction of azides with other carbocations is underway and will be reported in due course. 22

Acknowledgments We thank the National Institutes of Health (GM-35572) and the University of Michigan (Sokol Predoctoral Fellowship to J.M.S.) for support of this research.

\section{REEERENCES AND NOTES}

1. For example, the Beckman, Curtius, Hoffman, Schmidt, Stieglitz, and related rearrangements. See March, J., Advanced Organic Chemistry; J. Wiley \& Sons, Inc.: New York; 3rd Ed., 1985, Chapter 18.

2. Smith, P. A. S. In Molecular Rearrangements; de Mayo, P., Ed.; Wiley: New York, 1963; Part 1, pp 457591. The Stieglitz rearrangement also includes systems with only one carbon substitutent on the nitrogen. 
3. (a) Gassman, P. G.; Fox, B. L. J. Am. Chem. Soc. 1967, 89, 338-342. (b) Gassman, P. G. Accts. Chem. Res. 1970, 3, 26-33 and references therein. (c) Gassman, P. G.; Carrasquillo, A. Tetrahedron Lett. 1971, 109-112. (d) Gassman, P. G.; Hartman, G. D. J. Am. Chem. Soc. 1973, 95, 449-454.

4. Wasserman, H. H.; Adickes, H. W.; de Ochoa, O. E. J. Am. Chem. Soc. 1971, 93, 558-559.

5. Kovacic, P.; Liu, J.-H.; Levi, E. M.; Roskos, P. D. J. Am. Chem. Soc. 1971, 93, 5801-5805.

6. (a) Schell, F. M.; Ganguly, R. N.; Percell, K. S.; Parker, J. E., III, Tetrahedron Lett. 1979, 4925-4928. (b) Schell, F. M.; Ganguly, R. N. J. Org. Chem. 1980, 45, 4069-4070. (c) Schell, F. M.; Smith, A. M. Tetrahedron Lett. 1983, 24, 1883-1884.

7. Fleury, J.-P.; Biehler, J.-M.; Desbois, M. Tetrahedron Lett. 1969, 4091-4094.

8. (a) Hoffman, R. V.; Cadena, R.; Poelker, D. J. Tetrahedron Lett. 1978, 203-206. (b) Hoffman, R. V.; Poelker, D. J. J. Org. Chem. 1979, 44, 2364-2369. (c) Hoffman, R. V.; Kumar, A. J. Org. Chem. 1985, 50, 1859-1863. (d) Hoffman, R. V.; Kumar, A.; Buntain, G. A. J. Am. Chem. Soc. 1985, 107, 4731-4736. (e) Hoffman, R. V.; Buntain, G. A. J. Org. Chem. 1988, 53, 3316-3321. (f) Hoffman, R. V.; Salvador, J. M. J. Chem. Soc., Perkin Trans. I 1989, 1375-1380. (g) Hoffman, R. V.; Salvador, J. Tetrahedron Lett. 1989, 30, 4207-4210.

9. Heesing, A.; Herdering, W. Chem. Ber. 1983, 116, 1081-1096.

10. (a) Wolff, H. Org. React. 1946, 3, 307-336. (b) Abramovitch, R. A.; Kyba, E. P. In The Chemistry of the Azido Group; Patai, S., Ed.; Wiley: New York, 1971; pp 221-329. (c) Banthorpe, D. V., In The Chemistry of the Azido Group; Patai, S., Ed.; Wiley: New York, 1971; pp 397-440. (d) Smith, P. A. S.; Derivatives of Hydrazine and Other Hydronitrogens Having N-N Bonds, Benjamin/Cummings: London; 1983, pp. 263-300. (e) Kyba, E. P. In Azides and Nitrenes: Reactivity and Utility; Scriven, E. F. V., Ed.; Academic Press: Orlando, 1984, pp 2-34. (f) Scriven, E. F. V.; Turnbull, K. Chem. Rev. 1988, 88, 297. 368.

11. Aube, J.; Milligan, G. L.; Mossman, C. J. J. Org. Chem. 1992, 57, 1635-1637.

12. Aube, J.; Milligan, J. Am. Chem. Soc. 1991, 113, 8965-8966.

13. For the intermolecular reaction of alkyl azides with trialkyloxonium salts or alkyl halides in the presence of silver perchlorate, see: (a) Pritzkow, W.; Pohl, G. J. Prakt. Chem. 1963, 20, 132. (b) Wiberg, N.; Schmid, H. K. Angew. Chem. 1964, 76, 381.

14. Prepared from cyclohexenone by the following sequence: (1) 3,4-methylenedioxyphenyllithium; (2) 1ethoxy-1-(trimethylsilyloxy)ethene, $\mathrm{LiClO}_{4}$; (3) $\mathrm{LiAlH}_{4}$; (4) $\mathrm{MsCl}, \mathrm{NEt}_{3}$; (5) n-Bu4N 3 , THF. For the lithium perchlorate-promoted substitution of allylic alcohols, see: Pearson, W. H.; Schkeryantz, J. S. J. Org. Chem. 1992, 57,0000.

15. Grob, C. A.; Sieber, A. Helv. Chim. Acta, 1967, 50, 2531.

16. (a) Gassman, P. G.; Cryberg, R. L.; Shudo, K. J. Am. Chem.Soc. 1972, 94, 7600. (b) See also Ref. 3a.

17. (a) Fisher, R. D.; Bogard, T. D.; Kovacic, P. J. Am. Chem. Soc. 1972, 94, 7599. (b) Fisher, R. D.; Bogard, T. D.; Kovacic, P. J. Am. Chem. Soc. 1973, 95, 3646.

18. (a) Grob, C. A.; Kaiser, A.; Renk, E. Chemistry and Industry (London), 1957, 598. (b) Wepster, B. M. Rec. Trav. Chim. 1952, 71, 1171.

19. Krabbenhoft, H. O.; Wiseman, J. R.; Quinn, C. B. J. Am. Chem. Soc. 1974, 96, 258.

20. For a good discussion of the regioselectivity of Stieglitz-type rearrangements, including bridged bicyclic systems, see Hoffman in Refs $8 \mathrm{c}$ and $8 \mathrm{e}$.

21. Olah has studied the structure of simple aminodiazonium ions by NMR spectroscopy: Mertens, A.; Lammertsma, K.; Arvanaghi, Massoud; Olah, G. A. J. Am. Chem. Soc. 1983, 105, 5657-5660.

22. Preliminary results in several other systems indicate that there is no requirement that the carbocation be benzylic. 